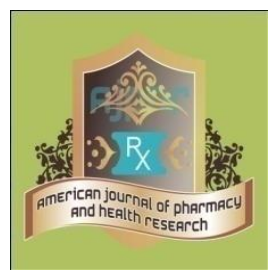

Research Article AMERICAN JOURNAL OF PHARMACY AND HEALTH RESEARCH

www.ajphr.com

2018, Volume 6, Issue 08

ISSN: 2321-3647(online)

\title{
Knowledge, Awareness and Practice among Consumers Towards Safe Disposal of Unused and Expired Medication in Urban Area of Dehradun District
}

\author{
Prashant Mathur*, Usha Pokhariya \\ Shri Guru Ram Rai Institute of Technology \& Science, Dehradun.
}

\begin{abstract}
Nowadays community disposes numerous unused and expired medicines via general waste or sewerage. Expired drug causes toxicity risk which allows the active substance to undergo dreadful condition. Various agencies have given different guidelines meant for disposing of the unused and expired medications, but there exists some discrepancies among these guidelines. The present study was intended to assess the knowledge, awareness and practice among consumers towards safe disposal of unused and expired medication in Urban Area of Dehradun District. To determine the possible threat/consequence of unusual disposing of medication with respect to environment. This prospective and observational study involving with the consumer based on self structured questionnaire, which involves data related to their socio-demographic data, practice employed for the dispose, awareness related to the environmental hazards and opinion for proper disposing methods. The study was carried out in Urban Area of Dehradun district for 6 months. A total of 200 consumers were included in the study. Total of 200 participants, 18 were non-respondent. Out of 182 participants, 117(64.28\%) were male while 65(35.71\%) were female. Among 182 participants $64(35.16 \%)$ were from the age-group of 26-35 years. Most of the participants $79(43.40 \%)$ were having graduate in their education level. Fifty eight $(31.86 \%)$ acknowledged that they keep drugs with them until expired and ninety eight (53.84\%) acknowledged that they throw away expired medication in household garbage. Out of 182 participants, 174(95.60\%) acknowledged that they note the expiry date on the medicines before purchasing. Sixty four (35.16\%), 66(36.26\%) and $75(41.20 \%)$ participants acknowledged method of disposal based on formulation type. One hundred forty seven (80.76\%)participants out of 182 aware towards environmental hazards by unused and expired medication. Among 182 participants 67(36.81\%) acknowledged that they utilized the take back programme that was based upon returning of unused and expired medication to the pharmacy. It was concluded in this study that practice for disposing unused and expired medications by consumers were not appropriate. Healthcare practitioners and community pharmacists should recommend guidance to educate consumers on measure medicine disposal practices.
\end{abstract}

Keywords: Disposal, Unused, Expired, Medicine, Consumers

*Corresponding Author Email: ushapokhria@gmail.com

Received 10 July 2018, Accepted 29 July 2018

INTRODUCTION:

Nowadays community disposes numerous unused and expired medicines via general waste or sewerage. ${ }^{[1]}$ Improper disposal system is a universal problem that occurs in both developing and

Please cite this article as: Mathur $\mathrm{P}$ et al., Knowledge, Awareness and Practice among Consumers Towards Safe Disposal of Unused and Expired Medication in Urban Area of Dehradun District. American Journal of Pharmacy \& Health Research 2018. 
developed countries. In developing countries, this problem is huge and not well defined. Expired drugs causes toxicity risk, which allows the active substance to undergo dreadful conditions. [2] Disposal of unused medicines into domestic waste is also show to landfill leachate and create environmental problems. ${ }^{[3]}$

Although, according to world health organization (WHO) authority, trace concentration of pharmaceutical substances in drinking water still in low concentrations are not likely to cause risks to human health. But at the same time, the same authority recognized that limited understanding exists about the potential health risk caused by long- term exposure to low levels of pharmaceutical substances in drinking water or combined effects of mixtures of pharmaceutical compounds. An active pharmaceutical ingredient (APIs) in the drinking water reveals the presence of the common drugs like antibiotics, anticonvulsant, analgesic and artificial hormones. ${ }^{[4]}$ Pharmaceutical products cross the threshold into the surroundings through improper disposal of unused and expired pharmaceutical measured quantity form in the toilet and sink. ${ }^{[5]}$ Pharmaceuticals differ from other environmental pollutants as they are created to be biologically active. It interacts with the partition following specific absorption, distribution, metabolism, and excretion properties. ${ }^{[6]}$ Pharmaceuticals can enter into the environment through various ways (Figure 1) depicted through production, distribution, purchased and consumed. 


\section{Source Pathways}

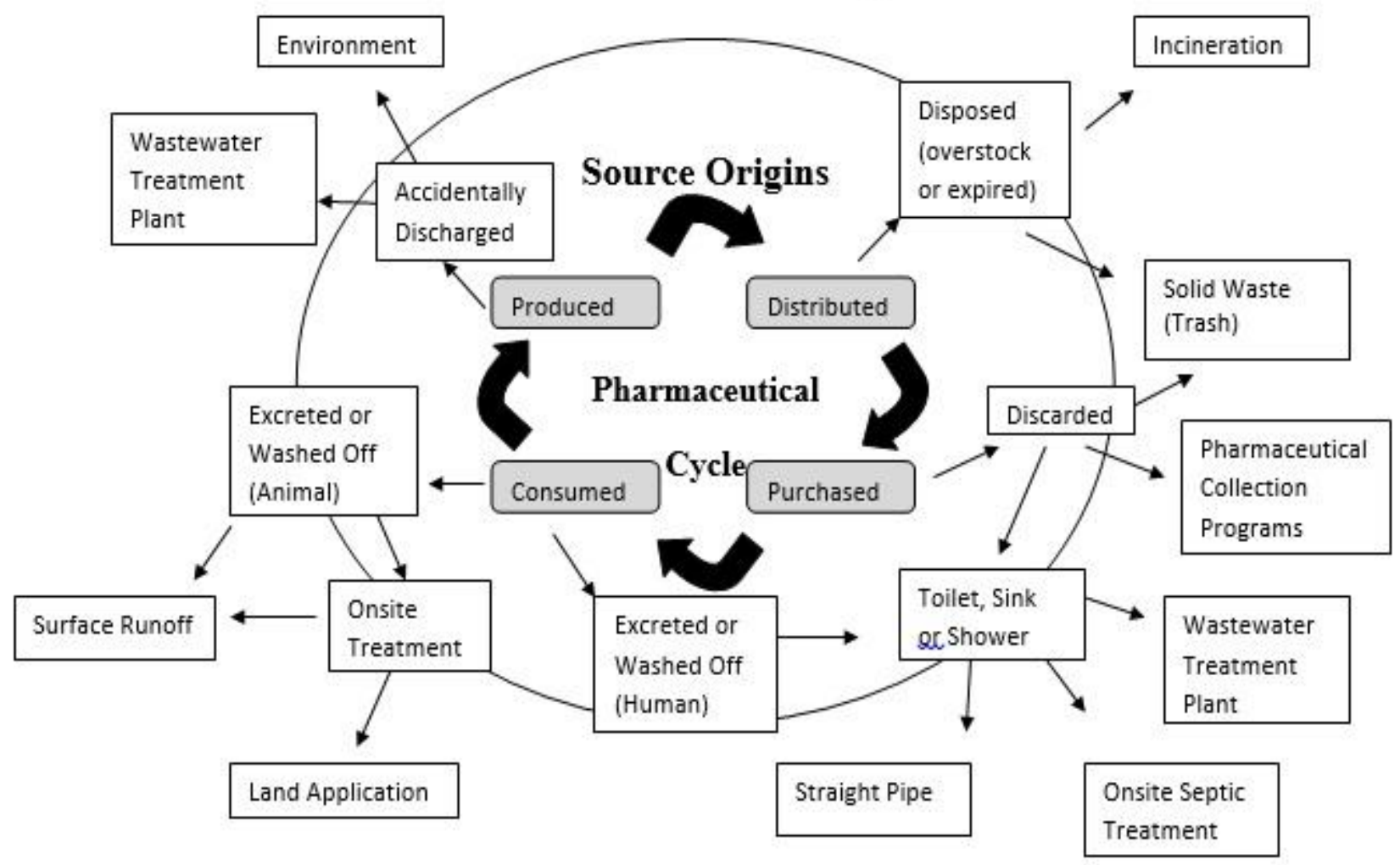

Figure 1: Entrance Pathways of medication in the environment. ${ }^{\text {[7] }}$

A medication if, improperly prescribed, sold, can cause preventable storage and creates an environmental threat. ${ }^{[8]}$ Improper disposal of medicines is associated with an environmental pollution and health hazards. ${ }^{[9]}$ Unused and expired medications are disposed off by flushing down the toilet and sink. The potential environmental contamination is caused in the water supply by entering rivers or lakes and passing throughout management systems. ${ }^{[10]}$ At the same time, U.S. Food and Drug Administration (FDA) is concerned regarding safe and proper disposals by mixing of these medications in either cat little or coffee grounds, as well as destroying the patient's name and medication information on the label. ${ }^{[11]}$

There is a lack of knowledge on how to dispose unused and expired medications among our participant residents. Some international and national studies showed that most consumers (patients) store their medication improperly at home. It may lead to unwanted effects or accidental risks like improper self-medication, unintentional overdose, and prescription drug abuse. Consumers normally keep their medications because they do not want to waste them, also they do not know how to read and check the expiry date, or they do not know a proper and safe way to dispose of them. ${ }^{[12]}$ 
The increasing awareness of the consequences of pollution from pharmaceuticals on the environment and its potential effects on human health, numerous international and government bodies recommend adopting strategies to minimize the quantity of pharmaceuticals that penetrate the natural surroundings. ${ }^{[13]}$ This suggestion left the timeline for implementing the policies and the support for providing consumers with safe disposal options to the individual governments. This strategy includes:

- Increased public awareness

- Guidelines and regulations

- Drug take-back programs

- Consumer education promote proper disposal of unused, unwanted, and expired medications.

\section{MATERIALS AND METHOD}

It was a prospective and observational study conducted among Consumers from Urban Area of Dehradun District. All the subjects were enrolled for the study based on the following inclusion and exclusion criteria.

\section{Inclusion and Exclusion Criteria}

Inclusion Criteria

Consumers above age of 18 years.

\section{Exclusion Criteria}

Consumers less than 18 years.

Consumers who are not willing to participate in the study.

\section{Study Duration}

The study was conducted for a period of six month.

\section{Ethics Committee Approval}

The study protocol was prepared and submitted. Ethical clearance was obtained from Institutional Ethics Committee (EC) for Research on human subjects. The study was approved and ethical clearance certificates were obtained.

\section{Study Design}

A total 200 consumers from the Urban Area of Dehradun District were randomly selected for the study. All the participants were interviewed based on a structured questionnaire containing questions regarding knowledge, awareness and practice used for disposing off the unused and expired medications. Questionnaire was designed separately for consumers. 
The Questionnaire designed consisted of 4 types of questions:

1. Socio-demographic data

2. Practice employed for the dispose.

3. Awareness related to the environmental hazards.

4. Opinion for proper disposing methods.

The questionnaire consist the basic information regarding the explanation of expiry date and most important the current status of disposing of unused and expired medication by consumers. The awareness towards environment pollution by improper disposing of medication explained by consumers involve in the questionnaire.

The questionnaire filled by the consumers included in the study and after completion, the results calculated and concluded the objectives of the study.

\section{Content of leaflet}

An information leaflet regarding knowledge, awareness proper storage and disposal was provided to consumers. This include the knowledge and awareness used for disposing of the unused and expired medications, consequence of improper disposal on non-disposal, take back programme, do and don't of medication and guidelines for proper disposal of medicines.

\section{Statistical Analysis}

Statistical calculations were carried out in MS Excel using descriptive analysis.

\section{RESULTS AND DISCUSSION}

A total of 200 Consumers were included in the study from the Urban Area of Dehradun District. The structured questionnaires were prepared separately for the consumers. The questionnaire concluded the questions about the knowledge, awareness and practice regarding disposing of the unused and expired medications, method of disposing the medication and awareness about environmental hazards.

Demographic Characteristics:

Table 1 Demographic details of study population

\begin{tabular}{lllll}
\hline S.No. & Variables & & No. of Participants & Percentage(\%) \\
\hline 1 & Gender & Male & 117 & 64.28 \\
& & Female & 65 & 35.71 \\
2 & Age (Years) & $18-25$ & 56 & 30.76 \\
& & $26-35$ & 64 & 35.16 \\
& & $36-45$ & 36 & 19.78 \\
& & $46-55$ & 14 & 7.69 \\
& & $56-40$ & 12 & 6.59 \\
3 & Education Status & Illiterate & 15 & 8.24 \\
\hline
\end{tabular}




\begin{tabular}{lll}
\hline High School & 28 & 15.38 \\
Intermediate & 24 & 13.18 \\
Graduate & 79 & 43.40 \\
Post graduate & 36 & 19.78 \\
\hline
\end{tabular}

In the present study out of 200 participants, 18 were non- respondent. Out of 182 participants, $117(64.28 \%)$ were male while $65(35.71 \%)$ were female. Most of the participants $64(35.16 \%)$ were from the age group of 26-35 years, followed by 56(30.76\%) under the age group 18-25 years, 36(19.78\%) under the age group 36-45 years and least participants 14(7.69\%) and $12(6.59 \%)$ under the age group 46-55 and 56-60 years respectively. Out of 182 participants, $79(43.40 \%)$ were graduate, 36(19.78\%) post graduate while 28(15.38\%), 24(13.18\%) and 15(8.24\%) subjects were high school, intermediate and illiterate respectively.

\section{Practice \& attitudes towards unused \& expired medication disposal}

Among 182 participants, 58(31.86\%) acknowledged that they keep drugs with them until expired, 42(23.07\%) told that they throw away these medication in household garbage and $51(28.02 \%)$ acknowledged that they return these unused medication to medical stores.

Ninety eight $(53.84 \%)$ participants acknowledged that they throw away expired medication in household garbage, 32(17.50\%) acknowledged return to medical stores and 31(17.03\%) acknowledged that they flush expired medication in toilet or sink.

Table 2: Respondents practice \& attitudes concerning unused \& expired medication disposal

\begin{tabular}{llll}
\hline S. No. & Response & \multicolumn{2}{c}{ No. of Respondents (\%) } \\
& & Unused (\%) & Expired (\%) \\
\hline 1. & Throw away in household garbage & $42(23.07)$ & $98(53.84)$ \\
2. & Donate to hospital & $20(10.98)$ & $6(3.29)$ \\
3. & Give to friends/ relatives & $6(3.29)$ & $5(2.74)$ \\
4. & Return to medical stores & $51(28.02)$ & $32(17.50)$ \\
5. & Flush unused medication in toilet or sink & $5(2.74)$ & $31(17.03)$ \\
6. & Keep at home until expired & $58(31.86)$ & $10(5.49)$ \\
\hline
\end{tabular}

\section{Knowledge about purchasing medicines}

Out of 182 participants, 174(95.60\%) acknowledged that they note the expiry date on the medicines before purchasing. Three (1.64\%) they don't seen the expiry date and 5(2.74\%) responded that they are not aware about checking expiry date of the medicines respectively. 


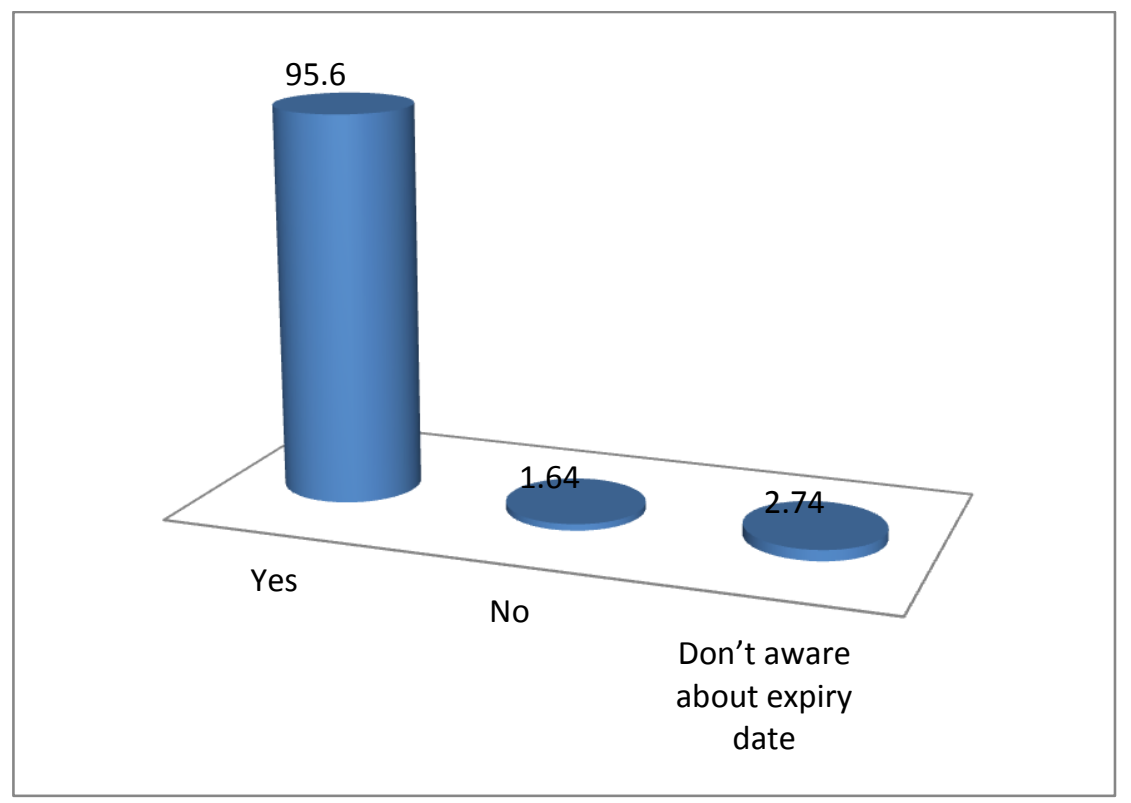

Figure 3:Respondents views about checking expiry date of the medicines before purchasing Disposing method

Table 4: Respondents methods of disposal depending on medication formulation type

\begin{tabular}{lllll}
\hline S. No. & Response & \multicolumn{3}{c}{ Medication formulation type } \\
& & SOLID(\%) & LIQUID(\%) & SEMI-SOLID(\%) \\
\hline 1. & With household rubbish bin & $64(35.16)$ & $66(36.26)$ & $75(41.20)$ \\
2. & Down the sink & $20(10.98)$ & $57(31.31)$ & $9(4.94)$ \\
3. & Down the toilet & $28(15.38)$ & $21(11.53)$ & $5(2.74)$ \\
4. & Medicine bin & $17(9.34)$ & $14(7.69)$ & $25(13.73)$ \\
5. & Return to pharmacy & $35(19.23)$ & $13(7.14)$ & $55(30.21)$ \\
6. & Others & $18(9.89)$ & $11(6.04)$ & $13(7.14)$ \\
\hline
\end{tabular}

Among 182 participants 64(35.16\%) of the respondents dispose off unused and expired solid medication in a household rubbish bin, while $35(19.23 \%)$ return the unused an expired solid medication to a pharmacy.

With respect to liquid dosage forms, 66(36.26\%) participants reported disposing off these in a manner that leads to their ending up in a house hold rubbish bin. Fifty seven $(31.31 \%)$ respondents dispose off unused and expired liquid medication down into the sink.

Lastly, responses to the question concerning semisolid indicated that less than $5(2.74 \%)$ of the respondents disposed off this type of medication via the toilet, with 55(30.21\%) returning unused and expired semi-solid medication to the pharmacy.

Awareness of the consumers towards environmental hazards by unused and expired medication 
In the present study, the awareness of the consumers towards environmental hazards by unused and expired medication. Among 182 participants, 147(80.76\%) aware towards environment while $35(19.23 \%)$ responded that they are not aware towards environment.

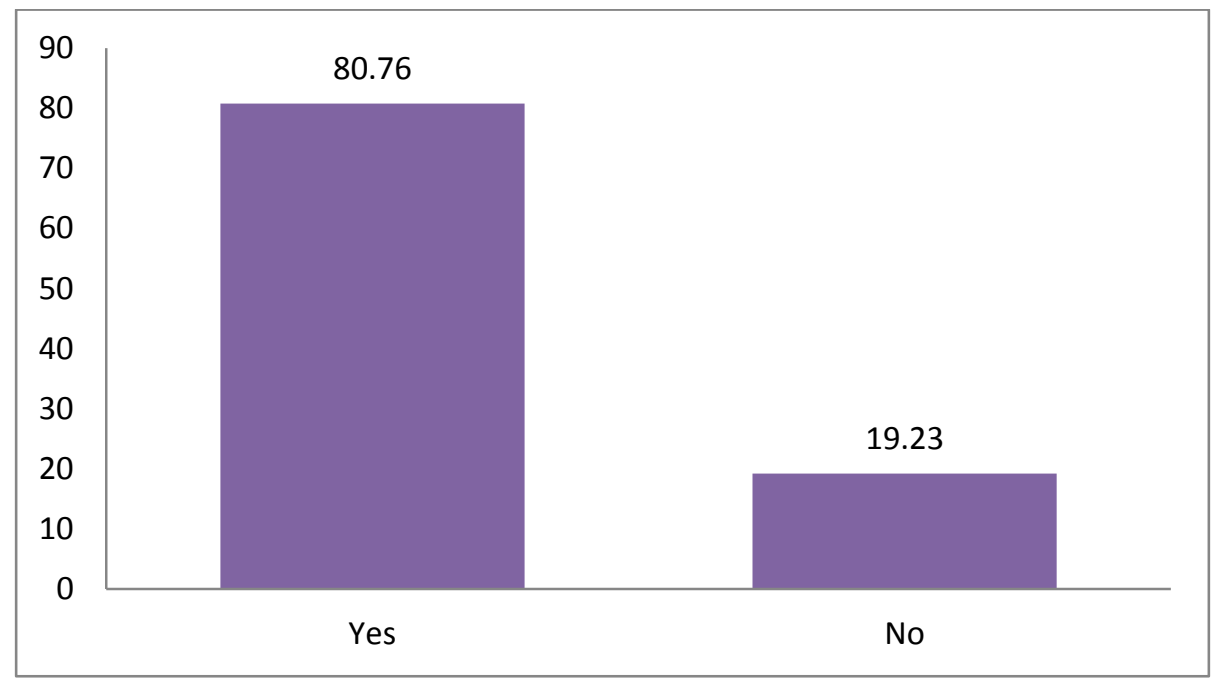

Figure 7- Response awareness of the consumers towards environmental hazards by unused and expired medication

\section{Environmental Damage}

Among 182 participants, 89(48.90\%) acknowledged that improper disposing of medication may cause some damage to the environment, 39(21.42\%) participants acknowledged that they do not know improper disposing of medication may cause environment damage. Thirty six (19.78\%) participants acknowledged that they may cause serious damage and $18(9.89 \%)$ participants may cause no damage respectively.

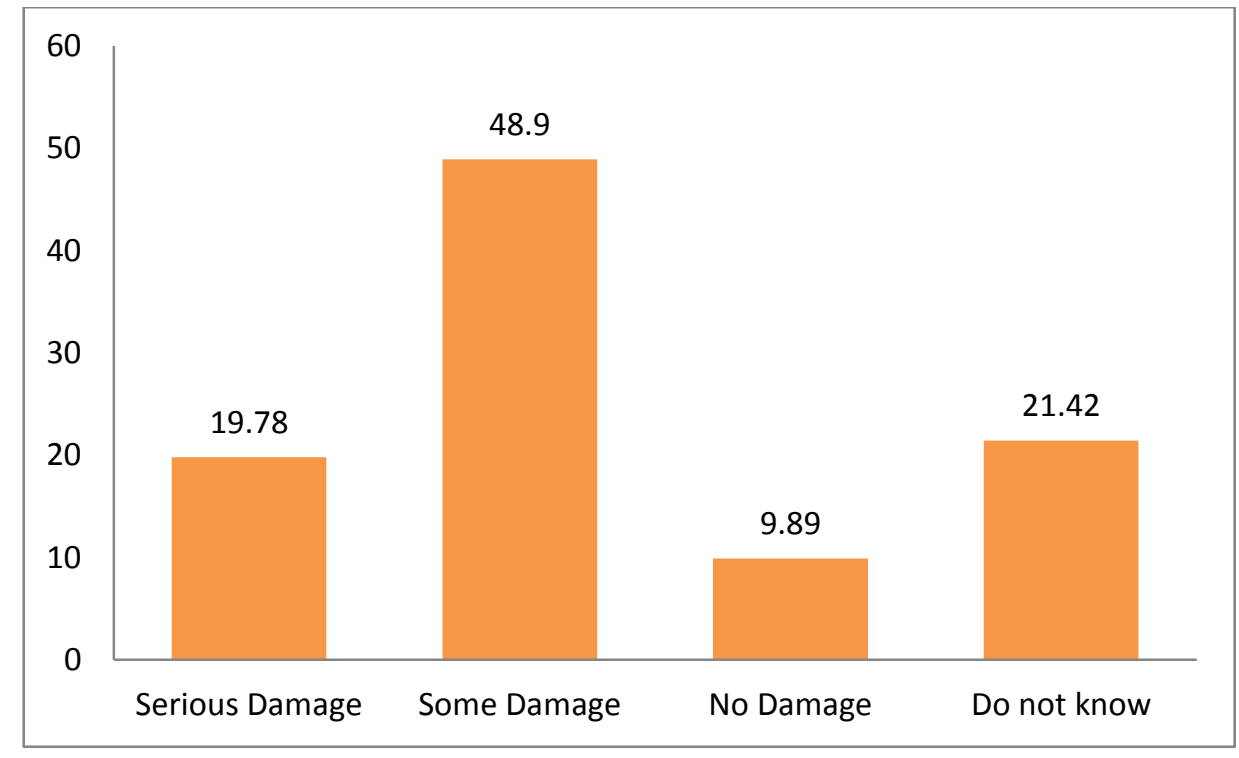

Figure 8 Response environment damage by the consumers 


\section{Time as Barrier}

Among 182 participants, 64(35.16\%) responded that returning of unused \& expired medication is time taking process. But 118(64.83\%) participants responded this is not a time taking process.

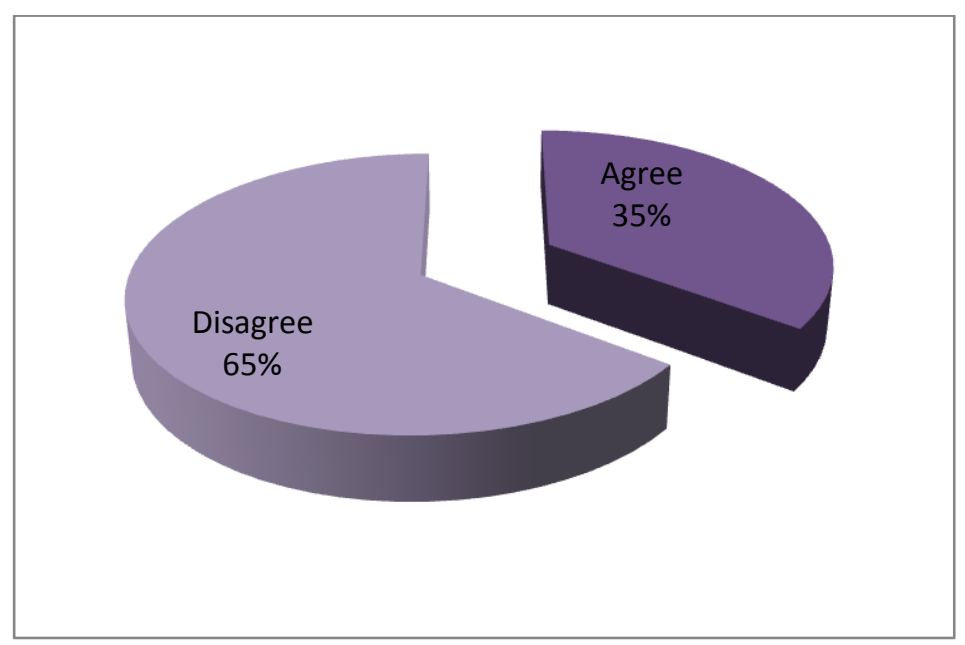

Figure 9:Response about returning of medication time as barrier

\section{Take back programme}

Among 182 participants, 67(36.81\%) acknowledged that they utilized the take back programme that was based upon returning of unused \& expired medication to the pharmacy. Thirty three $(18.13 \%)$ and $3(1.64 \%)$ participants were aware about the hospital and mail based take back programme. Out of 182 participants, 79(43.40\%) acknowledged that they utilized the regular based method which includes dispose of unused \& expired medication in their premises, flushing of waste medication into sink and toilets.

Table 10- Response type back programme utilizing by the consumers

\begin{tabular}{llll}
\hline S. No. & Type of take back programme & No. of Respondent & Percentage \% \\
\hline 1. & Pharmacy based & 67 & 36.81 \\
2. & Hospital based & 33 & 18.13 \\
3. & Police station based & 0 & 0 \\
4. & Mail based & 3 & 1.64 \\
5. & Regular based & 79 & 43.40 \\
\hline
\end{tabular}




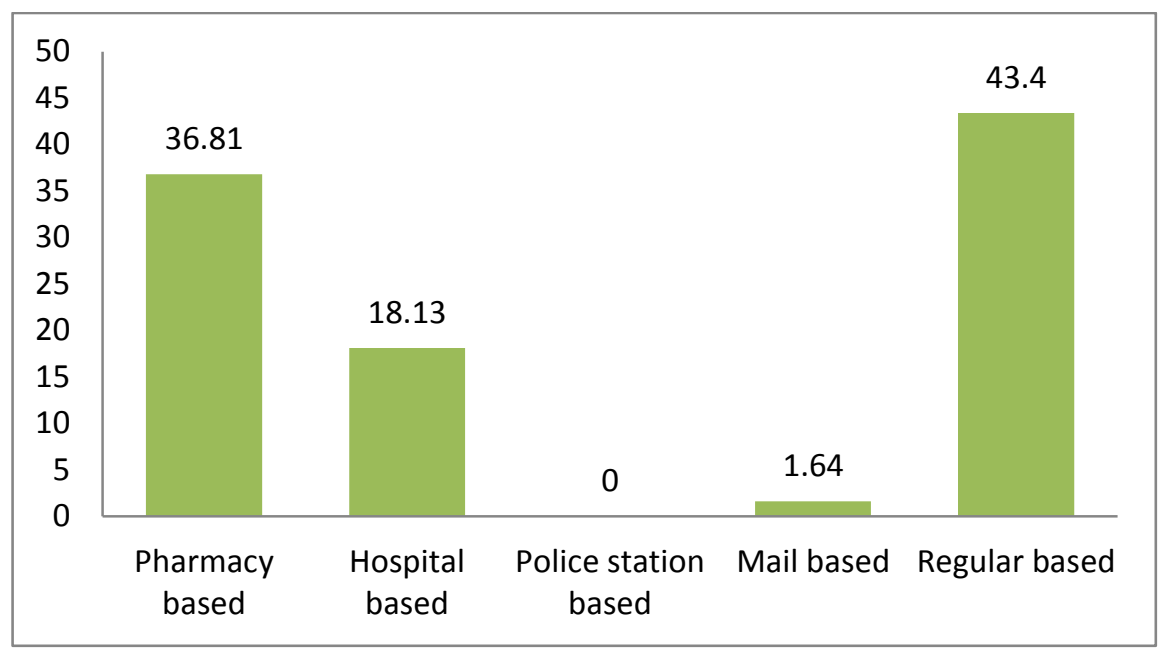

Figure 10: Response type back programme utilizing by the consumers

\section{Other disposing management}

Out of 182 participants, 87(36.81\%) answered other type of disposing management, 56(30.76\%) participants answered that they throw away and 39(21.42\%) participants answered that they burn respectively.

Table 11 Response other disposing management

\begin{tabular}{llll}
\hline S. No. & Type of other disposing & No. of Respondent & Percentage \% \\
\hline 1. & Throw away & 39 & 21.42 \\
2. & Burn & 56 & 30.76 \\
3. & Other & 87 & 36.81 \\
\hline
\end{tabular}

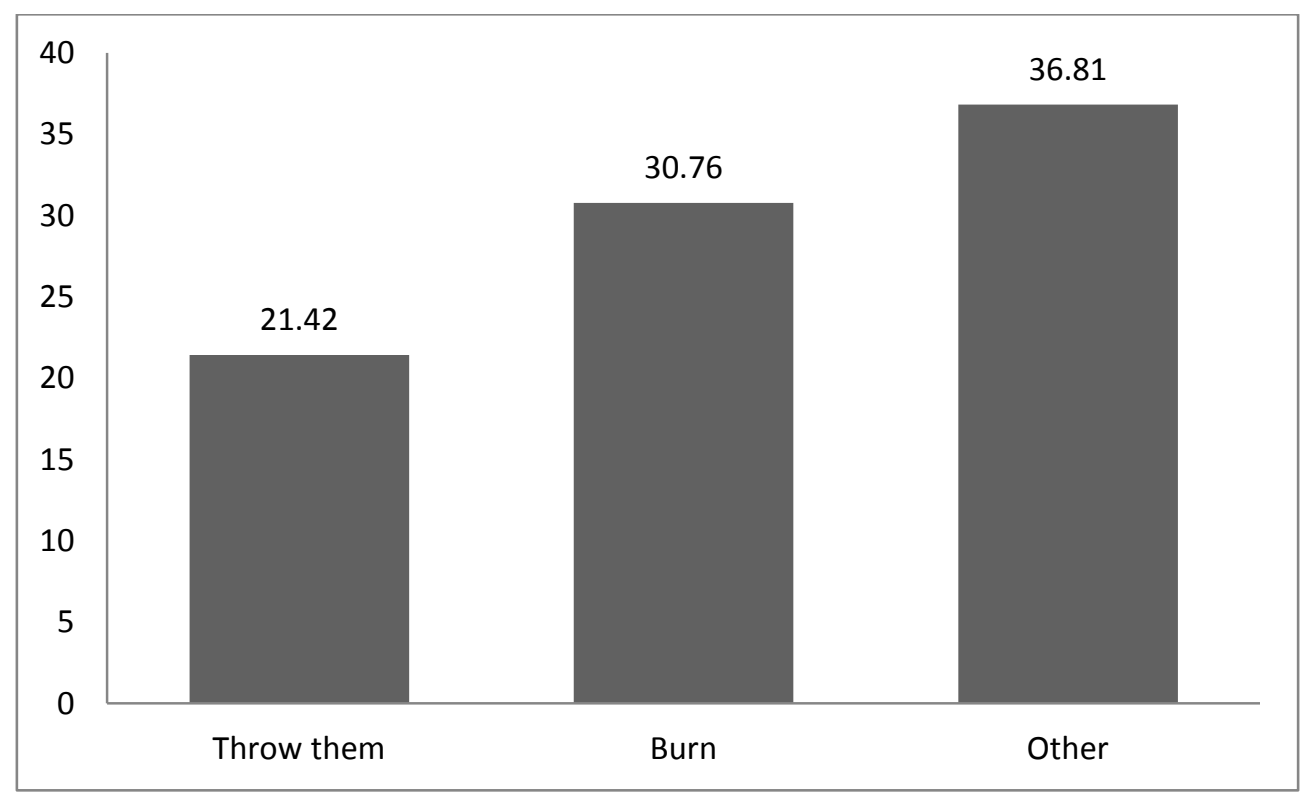

Figure 11: Response other disposing management

Currently, medical waste management and disposal is a hot topic grabbing attention because it has been realized that improper disposal can contaminate humans and the natural environment. 
Drug take-back programs are well established in certain countries where the pharmacy and the pharmacists have significant roles as collection points and as an exponent for proper disposal respectively. ${ }^{[7]}$ The present study aims to assess knowledge, awareness and practice among consumers towards safe disposal of unused and expired medication in the urban area of Dehradun district. All the subjects, in the present study were interviewed on the basis of a separate self-structured. The questionnaire included data regarding socio-demographic, practice employed for the dispose of awareness related to the environmental hazards and opinion for proper disposing methods. And a concise information leaflet containing awareness and existing guidelines for safe disposal of unused and expired medications were distributed.

In the present study, practice and attitude towards disposal of unused and expired medication was assessed. The study revealed that (53.84\%) of the respondents surveyed had leftover medication at home and half of the interviewed respondents used to keep the unused medication at home until expired. The result of the present study was similar to the practice followed by the consumer in Kabul. According to other study, the study stated that borrowing and sharing of medication is known to be associated with several risk factors such as polypharmacy and multiple, chronic morbidity. ${ }^{[14]}$

In the present study, nearly all (95.60\%) respondents acknowledged that they check the expiry date of medicine before purchasing. This study was similar to a study conducted by Bashaar M et $a l$. it is a vital consequence that earlier to purchase or use of any medicine, the expiry date must be checked; otherwise, it may lead to severe harmful effects. ${ }^{[15]}$

Present study shows that the consumers were not aware of the returning of unused and expired medications and various take-back programmes. In support of the present study, the previous study also showed the similar result about the awareness of the general public and healthcare professionals towards the proper disposing of unused and expired medication. ${ }^{[16-17]}$ The previous study was conducted through the survey and elucidated the current method of disposing and knowledge about the hazardous risk to the environment and human health. The previous study also focuses on the utilizing the various take-back programme by consumers. The studies elucidate that the awareness among the pharmacists and consumers towards the proper disposing of unused and expired medication and provide the knowledge for utilizing the various take-back programme for the prevention of hazardous risk to the environment. ${ }^{[18]}$

The primary aim of the present study was to assess the current criteria for disposing of the medication waste by consumers. The result of this study suggested that there is a major role of patient education for the proper disposal of unused and expired medication. 
During the study, pharmacists acknowledged that they will dispose the medication according to the guidelines in future and also aware the consumers about the proper disposing method and utilization of various take-back programmes. The consumers and the healthcare practioner indicated that they are personally responsible for protecting the environment and prevention of the living species from such hazardous risks.

\section{CONCLUSION}

This study finding has demonstrated that most of the consumers were not following appropriate practice for disposing unused and expired medications. The lack of knowledge about the impact of improper disposing of unused and expired medication may lead to the environmental hazards and the human health.

The practice of consumers towards the disposing of unused and expired medications concluded in the present study. The consumer subjects were not much aware about the actual meaning of expired medication. The most preferred disposing method of unused and expired medication by the consumer was throw in open and specific method were burn the expired medication, flush them into the toilet or sink. Very few people acknowledge that they returned the expired medication to the pharmacists. Most of the subjects in the study were aware about the environmental hazards from the improper disposing of unused and expired medication. A few subjects explained that the returning of unused and expired medication to the pharmacy is a very time taken process.

The study focus on the need to collect more information about the proper methods of disposing of unused and expired medication waste, identify proper guidelines for disposing off, their impacts on human health and environment and also further management system of proper disposing of unused and expired medication.

\section{REFERENCE}

1. Bergen PJ, Hussainy SY, George J, Kong DC, Kirkpatrick CM. Safe disposal of prescribed medicines. Australian Prescriber. 2015; 38(3):90.

2. Temu MJ, Kaale E, Marawiti M. Storage of anti malarial at household level and associated factors in Kiromo ward, Bagamoyo Tanzania. African Health Sciences. 2006; $6(1): 43-8$.

3. Bound JP, Voulvoulis N. Household disposal of pharmaceuticals as a pathway for aquatic contamination in the United Kingdom. Environmental Health Perspectives. 2005; 113(12): 1705 . 
4. Talerico DD. Pharmacuetical Pollution Prevention: An Examination of Medication Disposal Systems in Washington, Maine, New York, the San Francisco Bay Area, and Rhode Island. 2000

5. Ruhoy IS, Daughton CG. Types and quantities of leftover drugs entering the environment via disposal to sewage revealed by coroner records. Science of the total environment. 2007; 388(1-3):137-48.

6. Fatta-Kassinos D, Meric S, Nikolaou A. Pharmaceutical residues in environmental waters and wastewater: current state of knowledge and future research. Analytical and bioanalytical chemistry. 2011; 399(1):251-75.

7. Glassmeyer ST, Hinchey EK, Boehme SE, Daughton CG, Ruhoy IS, Conerly O, Daniels RL, Lauer L, McCarthy M, Nettesheim TG, Sykes K. Disposal practices for unwanted residential medications in the United States. Environment International. 2009; 35(3):56672.

8. West LM, Diack L, Cordina M, Stewart D. A cross-sectional survey of the Maltese general public on medication wastage. International Journal of Clinical Pharmacy. 2016; 38(2):261-70.

9. Medhi B, Sewal RK. Ecopharmacovigilance: An issue urgently to be addressed. Indian journal of pharmacology. 2012; 44(5):547.

10. Kozak MA, Melton JR, Gernant SA, Snyder ME. A needs assessment of unused and expired medication disposal practices: A study from the Medication Safety Research Network of Indiana. Research in Social and Administrative Pharmacy. 2016; 12(2):33640.

11. Food and Drug Administration. How to Dispose of Unused Medicines. Accessed 20.04.17.

12. De Bolle L, Mehuys E, Adriaens E, Remon JP, Van Bortel L, Christiaens T. Home medication cabinets and self-medication: a source of potential health threats?. Annals of Pharmacotherapy. 2008; 42(4):572-9.

13. World Health Organization. Pharmaceuticals in drinking water. Geneva, Switzerland: Author. 2011

14. Akhter N. Medication management: A review. School of environment, resources and development. 2000.

15. Bashaar M, Thawani V, Hassali MA, Saleem F. Disposal practices of unused and expired pharmaceuticals among general public in Kabul. BMC public health. 2017; 17(1):45. 
16. Dean A, Edwards S, Edwards J. Patient practice and beliefs concerning disposal of medications. J Am Board Fam Med, 2006; 19(6): 542-547.

17. Stergachis A. Promoting the proper disposing of unwanted, unused and expired medication. Journal of American Pharmacy Association. 2003; 54:226.

18. Abahussain E, Waheedi M, Koshy S. Practice, awareness and opinion of pharmacists towards the disposal of unwanted medication in Kuwait. Saudi pharmaceutical journal, 2012; 20(3):195-201. 